\title{
CULTURA POLÍTICA E ESTUDOS DE PODER LOCAL ${ }^{1}$
}

Maria Salete Souza de Amorim

\begin{abstract}
Resumo
Há um debate na Ciência Política contemporânea de que valores culturais são elementos importantes na análise do processo político. Ele torna-se profícuo na medida em que se reconhece que, além das instituições, os aspectos culturais contribuem para o fortalecimento do regime democrático. Este artigo tem como objetivo avaliar a qualidade da democracia a partir de estudos de poder local, verificando os indicadores de confiança e de participação política na construção de uma cultura política democrática. Os resultados da pesquisa mostram que o ceticismo e o conseqüente afastamento dos cidadãos da esfera da política comprometem atitudes e comportamentos favoráveis à democracia.
\end{abstract}

Palavras-Chave: Cultura Política; Poder Local; Paraná; Confiança; Participação Política.

\begin{abstract}
There is a debate on contemporary Political Science suggestions that cultural values are important elements in the analysis of the political process. The debate is enhanced by the recognition that, besides the institutions, the cultural aspects contribute to the strength of the democratic system. Based on these arguments this article seeks to evaluate the quality of democracy based on the local power studies, verifying the indicators of reliance and political participation in the construction of a democratic political culture. The results of this research confirmed that the skepticism and the citizens' withdrawal from the political sphere compromise attitudes and behaviors favorable to democracy.
\end{abstract}

Key-Words: Political Culture; Local Power; Paraná; Trust; Political Participation.

\section{Introdução}

Os estudos sobre política municipal são relevantes para compreender e caracterizar aspectos do sistema político mais amplo e das relações de poder que se estabelecem entre a esfera municipal, estadual e federal. Recentes pesquisas sobre a política no Estado do Paraná, especialmente nos municípios de pequeno e médio porte, revelam a coexistência de valores democráticos com práticas políticas tradicionais, que têm contribuído para o descrédito dos cidadãos em relação à política. O predomínio do clientelismo e do nepotismo nos processos políticos e eleitorais imprime um caráter personalista à

\footnotetext{
${ }^{1}$ Este artigo é parte de minha tese de doutorado, defendida em novembro de 2006.
} 
política municipal, marcada por uma matriz histórico-estrutural conservadora e autoritária.

Este artigo tem como objetivo propor a cidade como unidade de análise, tendo em vista avaliar a qualidade da democracia a partir da formação de valores, normas e atitudes políticas dos cidadãos frente à política local e nacional. Utilizam-se dados de pesquisa realizada na região Oeste do Paraná. Parte-se do pressuposto de que a confiança institucional e a participação política são importantes indicadores de uma cultura política democrática.

O texto divide-se em três seções. A primeira busca caracterizar aspectos do sistema político local e as relações de poder que se configuraram ao longo do processo histórico que se delineou no município de Toledo, PR, que completou 55 anos em dezembro de 2007. A segunda seção aborda o instrumental teórico da cultura política como importante categoria analítica na compreensão dos fenômenos políticos e sociais. Na seqüência, analisam-se os índices de confiança em relação às instituições políticas e os níveis de participação política verificados no município. Os resultados da pesquisa mostram uma avaliação bastante negativa por parte dos cidadãos em relação à atuação e ao desempenho dos políticos e baixos níveis de participação política. Esse quadro de ceticismo e de afastamento dos cidadãos da esfera da política compromete atitudes e comportamentos favoráveis à democracia.

\section{Poder local e Aspectos do Sistema Político Municipal}

Os estudos de poder local mostram-se relevantes na análise e compreensão dos aspectos do sistema político mais amplo. Certas características similares encontradas nestes estudos podem contribuir para explicar a dinâmica do sistema político em geral. Nos estudos de comunidade, a noção de política local refere-se às normas, instituições e comportamento político de âmbito regional. Nessas análises, ainda há pouco destaque para o papel do governo municipal enquanto "espaço político institucional em que se expressam a representação, a aliança, o confronto e a disputa de interesses, de forças e de organizações sociais 
que marcam e moldam o território político local, dentro do contexto regional e nacional" (KERBAUY, 2000, p. 28).

Nesta seção, busca-se verificar como a política de Toledo relaciona-se com a política estadual e nacional e quais as características e metas daqueles que dominam o poder local. Para pautar a discussão, são referidos alguns estudos que abordam o tema na perspectiva da cultura política e destacam a presença de traços tradicionais da política, como o clientelismo e o personalismo no processo político local.

Os autores Richard Fagen e Willian Tuohy (1972), ao analisar Jalapa, a segunda maior cidade no Estado de Veracruz, México, buscam explorar as características da política mexicana a partir da vida política nesta cidade. A pesquisa, de cunho quantitativo, procurou sondar as opiniões dos jalapenhos sobre a política, o governo e a atuação dos cidadãos enquanto atores políticos. Os dados revelam duas características da política local: a participação limitada e o predomínio do personalismo nos processos de decisão política. Os jalapenhos, além de expressarem ceticismo em relação à política, sentem-se impotentes em interferir ou afetar as decisões políticas locais.

A busca de soluções para resolver os problemas locais em Jalapa se dá de forma individual e baseada em relações afetivas, através de amigos, parentes ou compadres que têm melhores conexões com as autoridades políticas. Quando indagados sobre os direitos das minorias e sobre os grupos de oposição, os valores da democracia procedimental não se sustentam. A apatia, o sentimento de impotência e a indiferença para com as práticas democráticas formam a textura dominante das orientações políticas dos cidadãos em Jalapa (FAGEN e TUOHY, 1972).

No contexto brasileiro, o estudo de Beatriz Bilac sobre o município de Rio Claro aponta características semelhantes às de Jalapa. Como diversas localidades brasileiras, Rio Claro foi governado por chefes políticos locais que formavam uma oligarquia regional com estreitos laços econômicos e de parentesco. Com o processo de industrialização e urbanização, surgem novos atores políticos, o que não significou o afastamento da elite política tradicional, a qual mantém influência, ainda que indireta, no processo político local. O estudo reflete elementos do 
processo político mais amplo, caracterizando aspectos de uma política elitista ainda fechada à participação das classes populares na política (BILAC, 1997).

Por sua vez, o estudo de Monica Hass (2001) busca identificar em que medida os elementos político-partidários estaduais e nacionais interferem na questão do poder local. Segundo a autora, as transformações econômicas e o processo de redemocratização nos anos 1940 ocasionaram mudanças significativas na estrutura política de Chapecó, SC. Os políticos tradicionais, representantes do Partido Social Democrático (PSD), apesar de perderem espaço para os partidários da União Democrática Nacional (UDN) e do Partido Trabalhista Brasileiro (PTB), continuaram a dominar o cenário político ao longo do período de 1947 a 1965. A autora analisa que o continuísmo das elites tradicionais seu deu via controle de cargos públicos e de votos obtidos através da prática clientelista, estratégia política adotada para a manutenção do poder local.

Nessa perspectiva, Maria Teresa Kerbauy (2000), ao analisar a questão do poder local, destaca alguns elementos tradicionais intrínsecos a ele, como o coronelismo e o clientelismo. Ela concentrou o estudo no interior do Estado de São Paulo, examinando as mudanças institucionais ocorridas no período de 1964-82. A autora enfatiza que

$$
\begin{aligned}
& \text { a morte dos coronéis não significa o fim do clientelismo } \\
& \text { enquanto tal, assim como a modernização não significa } \\
& \text { a implantação da racionalidade burocrática e a } \\
& \text { ideologização da política. Permanece o clientelismo, } \\
& \text { como forma de controle social, para reduzir as pressões } \\
& \text { grupais, que se configuram, em muitos casos, em } \\
& \text { situações de conflito (KERBAUY, 2000, p. 144). }
\end{aligned}
$$

Observa-se que o clientelismo permanece num contexto de desenvolvimento e de mudanças institucionais, de modo que as novas relações políticas não implicaram no estabelecimento de políticas baseadas em critérios de natureza universalista. Os estudos de poder local aqui referenciados sobre diferentes contextos se aproximam por destacarem o predomínio da política elitista, da participação limitada, do 
personalismo e de práticas clientelistas como mecanismos e instrumentos da política municipal.

O trabalho de Gláucio Soares (2001) sobre as relações entre sociedade e política no Brasil indica que a elite dominante aceitava a liderança política como algo natural. A orientação era particularista, influenciada por relações interpessoais, em contraposição a orientações universalistas e ideológicas. O município era dominado por mais de uma família e uma dessas famílias,

geralmente se associava à UDN e a outra ao PSD, mas
algumas vezes elas se aborreciam com as decisões
nacionais ou estaduais do partido e simplesmente
escolhiam, entre outros partidos, um rótulo
conveniente pra continuar com a mesma política
tradicional de família (SOARES, 2001, p. 276).

Analisando as relações de poder no Paraná, Ricardo Costa de Oliveira (2001) endossa essa discussão, afirmando que o conjunto de famílias tradicionais, inseridas na classe dominante, atravessa os séculos com um projeto hegemônico de dominação e reprodução do poder político no Paraná. A classe dominante paranaense se caracteriza por padrões de continuidades históricas, expressivas na posse do poder político, principalmente por parte dos grupos familiares tão antigos quanto o Paraná. O domínio do poder local sempre foi determinado pela posição social e pela posse de terras e, por vezes, herdado pelos membros das famílias dominantes.

Dessa forma, a história política de Toledo se insere em um contexto mais amplo da política nacional, marcada pelo nacionalismo, ocupação de territórios e defesa das fronteiras brasileiras, o que possibilita compreender as características sociais, econômicas e políticas da região Oeste do Paraná. Em 1951, a maior parte das terras demarcadas no Oeste do Paraná se encontrava vendida, em geral, para empresas colonizadoras. No ano seguinte o município de Toledo foi instalado oficialmente. As elites políticas locais, ao se apropriarem do poder, não faziam a distinção entre o público e o privado, naturalizando práticas como o patrimonialismo, o clientelismo e o nepotismo, vigentes até hoje na política local. 
A dinâmica da política local mostra-se submetida a uma lógica própria, marcada pelo continuísmo de lideranças que se percebem como os donos do poder e da municipalidade. "A cultura política tradicional, o poder local tradicional, cumprem papel conservador e defensivo dirigido a manter as assimetrias e os relacionamentos de subalternidade. Transformar esta cultura e lógica autoritária de poder vai levar muito tempo" (JARA, 1997, p. 231). A ascendência de lideranças pessoais sobre os partidos políticos imprime um caráter personalista à política toledana, configurando-se no município uma política marcada por uma matriz histórico-estrutural conservadora e autoritária, alheia à participação política popular e aos partidos políticos.

Na seção seguinte será abordado o referencial teórico da cultura política, tendo em vista elucidar a formação de valores, normas e atitudes dos cidadãos frente à política local e nacional.

\section{Atualidade do Conceito de Cultura Política}

No âmbito das Ciências Sociais, parte da literatura sustenta que a cultura é uma variável importante para compreender a estabilidade e as mudanças dos sistemas políticos. No Brasil, a estreita relação entre cultura e estrutura sempre suscitou polêmica. Nos anos 1930 e posteriormente nos anos 1960, a preocupação com o nacionalismo e com a identidade nacional predominou entre os intelectuais, considerados porta-vozes e intérpretes da ideologia nacionalista. $\mathrm{Na}$ busca por uma sociedade integrada cultural e politicamente, julgava-se necessário construir uma cultura nacional, homogênea e consensual, que permitisse a identificação dos indivíduos com símbolos, imagens e mitos nacionais (BARBALHO, 1998). O principal pressuposto era de que as crenças e os valores culturais representavam importantes elementos na configuração da identidade nacional e na sustentação de um sistema político.

Os estudos de caráter nacional detinham-se a verificar as características, traços e atributos de uma nação e a analisar a cultura como elemento unificador desta nação. Os estudos de cultura política, por sua vez, introduzem o conceito de subculturas, buscando verificar a 
relação entre os traços culturais de um povo e o seu sistema político. Através de pesquisa empírica e da operacionalização dos conceitos propostos, tais estudos ampliaram a perspectiva analítica iniciada pelos estudos de caráter nacional (SOUZA, 1989).

Os precursores dos estudos de cultura política, Gabriel Almond e Sidney Verba (1965), introduzem a estatística na pesquisa comparada, permitindo a observação de determinadas regularidades e a comparação de sistemas políticos, independentemente de suas diferenças culturais ou políticas. A pesquisa empírica realizada nos Estados Unidos, GrãBretanha, Alemanha, Itália e México, nos anos 1960, teve como objetivo caracterizar o sistema político democrático e verificar atitudes e valores compatíveis com a estabilidade e a legitimidade do regime. Os autores avaliam a estabilidade democrática a partir do grau de institucionalização dos procedimentos democráticos, de participação política e de confiança dos cidadãos nas instituições políticas.

A obra The Civic Culture (ALMOND e VERBA, 1965) emerge da confluência de várias correntes de pensamento: estudos de opinião pública, teoria macro-sociológica, psicologia social e técnica amostral de survey, refletindo preocupações da época com a estabilidade democrática em um contexto de modernização política. Influenciados pelas categorias parsonianas e weberianas de ação social, os autores definem cultura política como o padrão de atitudes e orientações políticas dos cidadãos em relação ao sistema político, internalizadas na dimensão cognitiva, afetiva e avaliativa.

O estudo empírico encontrou correlações entre o senso de competência política e o apoio positivo ao sistema político, entre confiança interpessoal e participação política. A cultura cívica, abordada pelos autores como cultura política democrática, é considerada como requisito básico para a institucionalização e a estabilidade da democracia. Trata-se de uma cultura política mista e balanceada, em que os indivíduos participam do processo político com passividade e deferência à autoridade. Nesse caso, a cultura cívica é resultado da combinação entre a orientação política tradicional e a orientação moderna de participação. Na pesquisa são encontradas culturas políticas 
mistas dentro da política interna de cada país, revelando aspectos de heterogeneidade cultural e dinâmica histórica diferentes (ALMOND e VERBA, 1965).

Esse conceito gerou controvérsias na comunidade acadêmica, especialmente em relação à perspectiva histórica adotada e aos parâmetros estabelecidos na interpretação dos dados. A coletânea The Civic Culture Revisited, publicada 20 anos depois, oferece uma revisão crítica dos pressupostos teóricos apresentados por Almond e Verba nos anos 1960. De acordo com Carole Pateman (1989), não há uma explicação convincente a respeito da relação entre o padrão de atitudes e a estrutura política das democracias. Ao associarem a cultura cívica ao paradigma liberal de democracia e conceberem os países industrializados - particularmente os Estados Unidos e a Inglaterra como modelos de democracias estáveis, Almond e Verba restringiram toda e qualquer análise dentro desse parâmetro.

Um dos argumentos de Pateman (1989) a respeito da obra em questão é de que a teoria liberal obscurece a mútua interação entre cultura e estrutura política, especialmente quando as diferenças socioeconômicas são tratadas como irrelevantes, e não confrontadas com a estrutura política das nações. A autora alega também que o parâmetro utilizado não encontrou formas análogas em países emergentes que garantissem a construção de um sistema político baseado nos moldes defendidos pelos autores da cultura cívica.

Em resposta às críticas, os autores Almond e Verba (1989) admitem que o modelo de cultura cívica é baseado na teoria política liberal, mas justificam que os modelos culturais específicos foram analisados dentro do marco histórico particular de cada nação. Argumentam que a cultura política foi tratada como variável dependente e independente, dentro de um modelo de causalidade recíproca, no qual cultura, economia e política exercem influências mútuas, excluindo o determinismo cultural de abordagens anteriores. Os autores reconhecem que a cultura política é uma plástica com muitas variáveis e que responde rapidamente pelas mudanças estruturais. 
Revisando as categorias conceituais da cultura política, Luis Madueño (1999) destaca quatro premissas: a) toda cultura política possui uma identidade relacional dentro de uma totalidade histórica; b) possui uma lógica estrutural própria; c) é parte de uma estrutura que marca a rede de relações entre economia e política; e d) é um conceito histórico. O autor define cultura política como

contexto onde encontramos um conjunto de
significados tecidos pelo homem e pelas instituições,
onde os atores individuais e coletivos se reconhecem
mutuamente e reproduzem as ações sociais e políticas
sobre a base de crenças, hábitos e rituais,
convertendo-se estas em regularidades de ação onde
restabelece força a dimensão tempo e espaço
(MADUEÑO, 1999, p. 124).

De acordo com o autor citado, cultura política possui um conjunto de potencialidades capaz de introduzir ferramentas de análise na medida em que surgem outros fenômenos, produto das mudanças da época.

As características da cultura política latino-americana apresentam diferentes nuances em cada um dos países da região. Roderic Camp (2001), juntamente com outros pesquisadores, realizou pesquisas no México, Costa Rica e Chile, com o objetivo de analisar as percepções dos cidadãos a respeito da democracia. Costa Rica foi selecionada por ser considerada o país mais democrático, cuja ênfase recai no pluralismo governamental e na política eleitoral. O México, por ser um dos países menos avançados institucionalmente para democracia, além da proximidade com os Estados Unidos. O Chile foi incluído por oferecer um interessante estudo de caso sobre as mudanças entre influências democráticas e autoritárias. Os legados do militarismo e autoritarismo mantiveram-se institucionalizados, apesar da efetivação democrática no Chile.

A pesquisa destaca a importância dos valores culturais na explicação do comportamento político e encontra relações significativas entre a maneira como os cidadãos percebem a democracia e a sua prática política. Os dados mostram que a maneira como os latinoamericanos concebem a democracia difere da visão dos cidadãos norteamericanos. O que mais distingue a versão de democracia latino- 
americana é sua ênfase na igualdade social e econômica. Contudo, os dados sugerem que não há um consenso sobre o significado de democracia entre os latino-americanos. Os costarriquenhos vêem a democracia como garantia da liberdade política aos cidadãos. Os mexicanos e os chilenos vêem a democracia mais em termos sociais do que políticos. Mas, no geral, a expectativa é o alcance da igualdade socioeconômica entre os cidadãos (CAMP, 2001).

No caso da experiência brasileira, esta tem demonstrado que a democratização é, antes de tudo, um processo positivo de criação institucional e de reconstrução da sociedade civil. Lamounier e Souza (1991) avaliam que as atitudes dos brasileiros para com a democracia mudaram de forma positiva e substancial, contribuindo para a transformação da cultura política, tornando-a mais democrática. A perspectiva de cultura política adotada pelos autores enfatiza os aspectos institucionais, alegando que a legitimidade e a estabilidade do sistema político dependem da estrutura institucional e da confiança dos cidadãos no processo eleitoral e no sistema de competição partidária.

Da mesma forma, instituições ineficientes contribuem negativamente para a institucionalização da democracia, na medida em que estimulam atitudes contrárias às práticas típicas de um regime democrático. Rennó (1999) propõe articular os pressupostos da teoria da escolha racional e da cultura política, visando construir um modelo analítico mais complexo sobre comportamento político. $\mathrm{O}$ autor argumenta que, ao combinar

$$
\begin{aligned}
& \text { o estudo dos valores, crenças e conhecimentos do } \\
& \text { indivíduo - que constituem o contexto cultural que o } \\
& \text { cerca - e o papel das instituições formais nesse } \\
& \text { ambiente, com a suposição de que as pessoas agem } \\
& \text { racionalmente, ou seja, apresentam razões para } \\
& \text { desenvolver certa atividade, possuem planos coerentes } \\
& \text { e visam maximizar preferências e minimizar custos, } \\
& \text { pode-se amenizar as dificuldades de uma abordagem } \\
& \text { exclusivamente racionalista e amplar a capacidade } \\
& \text { explicativa da perspectiva culturalista (RENNó, 1999, p. } \\
& \text { 105). }
\end{aligned}
$$

A pesquisa realizada por Rennó no Distrito Federal indica um contexto cultural caracterizado pela lógica da desconfiança e por um 
comportamento orientado pela informalidade. As predisposições dos cidadãos demonstram uma descrença generalizada nas instituições políticas e nos atores democráticos, contribuindo para o seu afastamento da esfera pública.

A institucionalidade informal tem se caracterizado pela presença do clientelismo nos processos políticos e reside fundamentalmente em uma cultura patrimonialista, na qual se concebe a política como uma extensão do espaço privado que permite satisfazer interesses particulares. O clientelismo reflete a relação política vertical e desigual vivida na região, contribuindo para reforçar essa situação. Tendo em vista as debilidades do desempenho institucional, Barreda e Costafreda (2004) destacam o surgimento de propostas de reformas institucionais no contexto latino-americano. Entretanto, os autores destacam que: 1) toda estratégia de reforma institucional que pretenda ser efetiva tem que ter um caráter integral; 2) não basta mudar o desenho das instituições políticas, mas é necessário mudar também a cultura política de uma sociedade.

A relevância do conceito de cultura política está em fornecer ferramentas de análise na explicação das predisposições e comportamentos políticos dos cidadãos. Enquanto conceito histórico e estrutural, a cultura política é uma variável importante que contribui para compreender a estabilidade e as mudanças dos sistemas políticos. Dessa forma, as pesquisas de opinião são fundamentais para avaliar crenças e atitudes políticas dos cidadãos em relação às instituições e à legitimidade do sistema político. Na seção seguinte serão analisados os indicadores de confiança institucional e os níveis de participação política observados no município de Toledo.

\section{Níveis de Confiança e de Participação Política}

Os dados analisados são provenientes de pesquisa realizada no município de Toledo, PR, em 2002, nos meses que antecederam as eleições para Presidente da República e para Governador do Estado. A pesquisa intitulada Comportamento Político e Decisão Eleitoral no Oeste do Paraná, teve como objetivo compreender a complexa rede de 
determinantes que envolvem a decisão eleitoral no município de Toledo $^{2}$. Na ocasião, foi constituída uma amostra não-probabilística de 300 eleitores, residentes na área urbana do município, com idade acima de 16 anos, e estratificada por bairro e sexo, segundo dados do Censo Demográfico de 2000. Dessa forma, os 21 bairros cadastrados pelo Instituto Brasileiro de Geografia e Estatística (IBGE) foram incluídos na amostra e a população masculina e feminina, distribuída proporcionalmente ao número da população por bairro/sexo levantada pelo IBGE.

Estudos produzidos nos últimos anos revelam que a confiança é um componente básico do capital social que, sob a forma de regras de reciprocidade e participação cívica, favorece a cooperação e a solidariedade social. O conceito de capital social visa potencializar a participação cidadã e capacitar os indivíduos para incidir de forma protagônica nos processos políticos, propondo saídas e alternativas criativas à crise política e social (BAQUERO, 2006).

Nessa direção, Nazzari (2002) argumenta que as principais variáveis de capital social, como confiança, cooperação e participação não estão sendo favorecidas pelo processo de socialização política vigente, contribuindo para o desenvolvimento de atitudes de apatia e indiferença em relação à política. Em estudo sobre a socialização política dos jovens paranaenses, a autora constatou que os mesmos carecem de valores democráticos, como confiança nas pessoas e nas instituições. Os resultados da pesquisa mostram que a descrença nos partidos e nos políticos é expressiva, e os fatores determinantes estão associados ao não cumprimento de promessas e às denúncias de corrupção. De acordo com Nazzari (2002, p. 195) faltam aos jovens "crenças em alguns valores democráticos fundamentais, como confiança nas pessoas e instituições, mais acentuadas nos valores transmitidos pela escola que pela família". Esse padrão de desconfiança também se observa em Toledo, conforme dados da Tabela 1.

2 O banco de dados está disponível no Núcleo de Documentação e Pesquisa da Universidade Estadual do Oeste do Paraná (Unioeste), Campus de Toledo, no software Statistical Package for Social Science - SPSS, o qual permite a descrição de freqüências e o cruzamento de variáveis. 
Tabela 1- Confiança nas Instituições (\%)

\begin{tabular}{lcccc}
\hline \multicolumn{5}{c}{ Qual o grau de sua confiança em relação a } \\
\hline & Muita & Pouca & Nenhuma & Total \\
\hline Televisão & 8 & 59 & 33 & 100 \\
Partidos Políticos & 8 & 60 & 32 & 100 \\
Ministros do Governo & 11 & 63 & 26 & 100 \\
Deputados e Senadores & 13 & 61 & 26 & 100 \\
Sindicatos & 15 & 57 & 28 & 100 \\
Polícia & 24 & 63 & 13 & 100 \\
Tribunais de Justiça & 26 & 59 & 15 & 100 \\
Igrejas & 58 & 35 & 7 & 100 \\
Cientistas e Professores & 65 & 32 & 3 & 100 \\
\hline n = 300 & \multicolumn{5}{c}{} \\
Fonte: Pesquisa Comportamento Político e Decisão Eleitoral, Toledo, 2002.
\end{tabular}

Os dados da Tabela 1 corroboram com dados de pesquisas nacionais e estaduais, revelando que a maioria dos toledanos deposita pouca confiança nas instituições políticas. Apenas $8 \%$ afirmam confiar nos partidos políticos e os demais expressam pouca ou nenhuma confiança. Da mesma forma, $13 \%$ dos entrevistados alegam confiar nos deputados e senadores. Os entrevistados argumentam que os políticos não cumprem suas funções de representar e mediar os interesses sociais, e que a maioria destes visa enriquecer à custa do dinheiro público e arrumar a vida de amigos e parentes, como mostram os dados da Tabela 2 e do Gráfico 1.

Tabela 2- Avaliação da Atuação dos Políticos (\%)

\begin{tabular}{|c|c|c|c|c|c|}
\hline \multicolumn{6}{|c|}{$\begin{array}{c}\text { Na sua opinião, os políticos cumprem as funções de fazer leis e } \\
\text { fiscalizar o uso do dinheiro público? }\end{array}$} \\
\hline & Sim & Não & Um pouco & Não Sabe & Total \\
\hline Vereadores & 18 & 27 & 43 & 12 & 100 \\
\hline Deputados Estaduais & 17 & 18 & 50 & 15 & 100 \\
\hline Deputados Federais e Senadores & 16 & 18 & 47 & 19 & 100 \\
\hline
\end{tabular}

Observa-se na Tabela 2 que não chega a $20 \%$ o percentual daqueles que acreditam que os políticos cumprem suas funções. Por outro lado, há um percentual significativo de eleitores que não sabem se os políticos cumprem ou não sua função, seja porque não fiscalizam, seja porque a maioria nem lembra em quem votou. Embora os percentuais de avaliação sobre a atuação dos vereadores sejam maiores 
em relação aos demais, os entrevistados também não souberam avaliar o trabalho dos deputados estaduais, apesar da proximidade com o seu cotidiano.

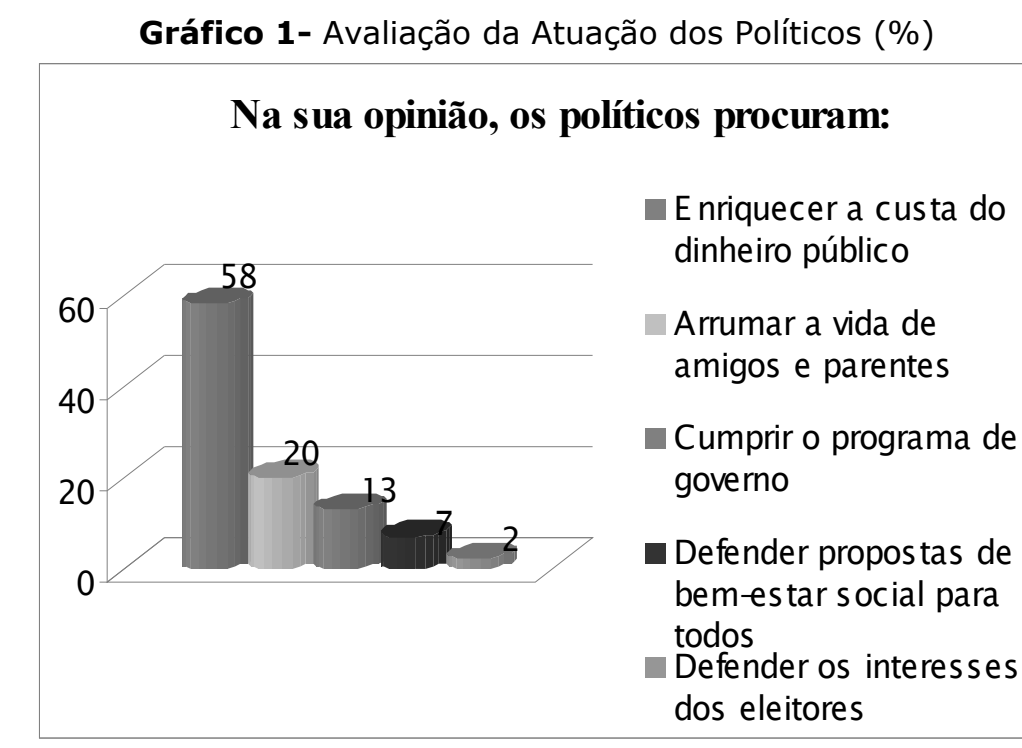

$\mathrm{n}=300$

Fonte: Pesquisa Comportamento Político e Decisão Eleitoral, Toledo, 2002.

Depreende-se dos dados do Gráfico 1 uma avaliação negativa sobre o desempenho dos políticos. Apenas $13 \%$ afirmam que os políticos buscam cumprir o programa de governo e 7\% alegam que os políticos defendem propostas de bem-estar para todos. Dentre os entrevistados, $2 \%$ acreditam que seus interesses estejam sendo defendidos pelos políticos. A opinião da maioria é de que os políticos procuram enriquecer a custa do dinheiro público (58\%). Essa postura pode ser justificada pelas demandas não atendidas e pelas inúmeras denúncias de corrupção na política nos últimos anos. Outros $20 \%$ acreditam que os políticos buscam arrumar a vida de amigos e parentes. Nesse contexto, o nepotismo, definido como a concessão de benefícios e cargos públicos a parentes, reflete uma das formas mais puras de corrupção na política e está presente hoje nas três esferas de poder: Executivo, Legislativo e Judiciário (BEZERRA, 1995).

Os resultados apresentados pela pesquisa elucidam um paradoxo. De um lado, os cidadãos expressam falta de credibilidade no 
Estado e na classe política, o que compromete sua motivação em participar nos processos decisórios. De outro lado, esperam do governo a resolução dos problemas socioeconômicos e, para tanto, transferem toda a responsabilidade a um líder, uma personalidade política escolhida pelo voto.

Esses indicadores de desconfiança institucional convergem com resultados de pesquisas realizadas no âmbito da América Latina que constatam a existência de uma cultura política híbrida e contraditória, na qual convivem elementos autoritários e democráticos. Dessa forma, as instituições democráticas são permeadas por uma cultura política orientada pelo individualismo, passividade, indiferença e desconfiança, que mantém a democracia em um estado permanente de instabilidade (BAQUERO, 2000; SCHMIDT, 2001). Diante da desconfiança em relação aos partidos políticos, os cidadãos se afastam da esfera política, refletindo em baixos índices de participação.

Os estudos sobre participação política mostram que há uma mobilização para o voto, uma das mais clássicas formas de participação e expressão política. Ainda que o voto não fosse obrigatório, 58\% dos entrevistados afirmam que votariam nas próximas eleições. Contudo, os índices de participação política no município de Toledo são bastante baixos, refletindo a desconfiança e a insatisfação dos cidadãos em relação ao desempenho do regime democrático, como mostra o Gráfico a seguir. 
Gráfico 2- Participação Política e Social em Toledo (\%)

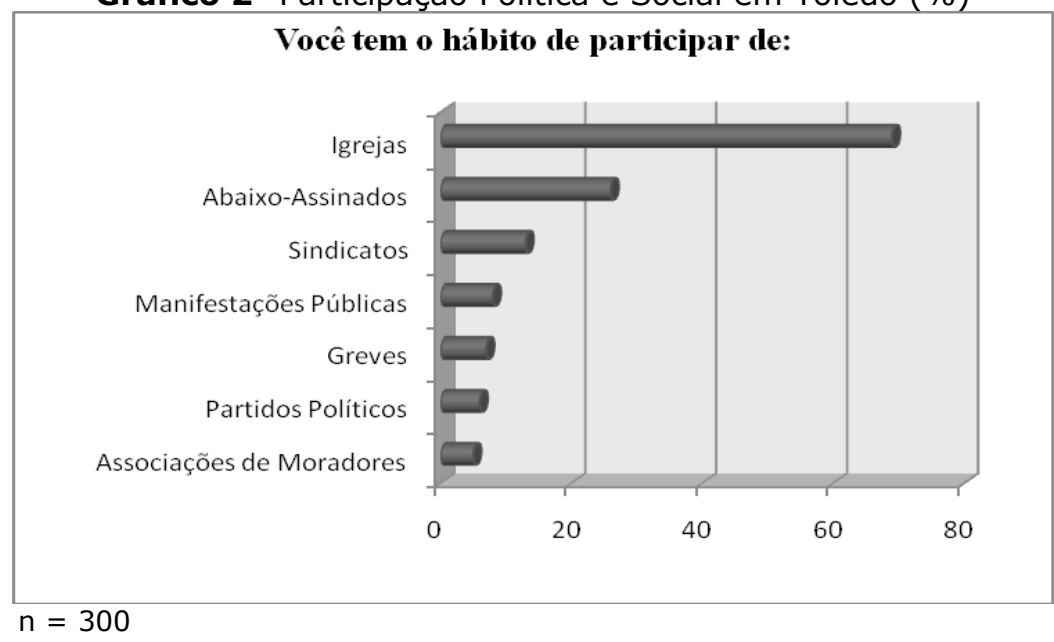

Fonte: Pesquisa Comportamento Político e Decisão Eleitoral, Toledo, 2002.

Embora a região Oeste paranaense tenha sido palco de significativas mobilizações no final dos anos 1970 e início dos anos 1980, pode-se depreender dos dados apresentados no Gráfico 2 que há pouca predisposição dos cidadãos toledanos para participar, tanto em atividades políticas consideradas convencionais (partidos políticos e campanhas eleitorais), como daquelas de caráter reivindicatório, como protestos e manifestações públicas, consideradas não convencionais.

Nazzari (2002) atribui a baixa participação política dos paranaenses, especialmente dos adolescentes, à cultura política personalista e autoritária que se configurou no estado. Segundo a autora, os paranaenses são pouco orientados para atitudes participativas pelas estruturas socializadoras (escola e família), que restringem e limitam a participação dos adolescentes nos processos de decisão. A análise histórica do Oeste do Paraná mostra que, desde cedo, os paranaenses convivem com relações paternalistas e exercem atividades políticas por meio de relações pessoais e de troca de favores.

Trazendo essa discussão para o município de Toledo observa-se que, apesar dos baixos índices, os toledanos consideram importante a participação da população nas decisões políticas. Portanto, entender a baixa participação política dos cidadãos envolve compreender as crenças e valores em relação à política e às instituições democráticas e os 
motivos para os baixos estoques de capital social. A perspectiva aqui adotada defende que a participação da população constitui um pressuposto decisivo para o fortalecimento das instituições democráticas e das organizações sociais, que propiciam à população possibilidades de se pronunciar e de ser incluída nos processos políticos.

O pressuposto é de que quanto maior a participação política, maior a probabilidade de se efetivar uma política que garanta direitos de cidadania, oportunidades de trabalho e renda, melhoria da qualidade de vida e eqüidade social. Participar é uma forma de exercer os direitos sociais e políticos garantidos pela Constituição. Segundo relatório divulgado pela Rede Interamericana para a Democracia,

participar es ser parte, tener parte, tomar parte, y esto
implica tres condiciones básicas: involucramiento,
compromiso y sentido de identidad. La participación
tiene como fin influir, pero influir en los procesos de
tomada de decisiones que de alguna manera se
vinculan con los intereses de los participantes y los
recursos que la sociedad dispone para ello (RID, 2005,
p.7).

A participação ativa dos cidadãos nos processos políticos, sociais e comunitários configura-se numa participação cidadã e tem como objetivo influenciar as decisões que contemplem os interesses sociais e o exercício da cidadania.

O Índice de Participação Cidadã é um instrumento orientado à avaliação periódica e sistemática dos níveis de participação na América Latina, e elaborado a partir de três indicadores: 1) participação direta, através dos canais formais e informais da política, incluindo partidos políticos, reuniões políticas, entidades sindicais, religiosas e comunitárias; 2) participação através da opinião pública, através do envio de artigos ou cartas a meios de comunicação e 3) participação eleitoral, avaliada pela predisposição dos cidadãos a participar de eleições e referendos, de partidos políticos e audiências públicas.

Estudos mostram que as motivações e atitudes dos eleitores estão diretamente relacionadas com a intensidade da participação política. O argumento de Putnam (2002) é de que o funcionamento da democracia é condicionado pela existência de vida associativa, pautada 
na confiança interpessoal, interesse político e participação política dos cidadãos. A participação política nas regiões de baixa vida associativa é permeada pela prática do clientelismo e do personalismo, e não por compromissos programáticos.

Dentro desse marco de análise, situam-se autores que argumentam que o declínio da participação tradicional e o aumento da desconfiança nas instituições políticas não devem ser vistos como uma ameaça à estabilidade democrática, pois não têm necessariamente um efeito negativo no sistema político. Os baixos índices de participação política verificados nas sociedades contemporâneas são decorrentes dos processos de pós-modernização e a conseqüente transformação global e estrutural dos padrões dos valores nas sociedades ocidentais, que têm contribuído para o surgimento de cidadãos mais críticos e abertos às novas formas de participação política. Para esses autores, a institucionalização de valores pós-materialistas e a ampliação do repertório de participação política são fundamentais para o fortalecimento da democracia (INGLEHART, 2002; STOLLE e HOOGHE, 2004).

Abordagens dessa natureza se distanciam um pouco da realidade brasileira, cujos valores pós-materialistas estão longe de se efetivar. Por sua vez, o declínio da participação e o aumento do ceticismo, no caso do Brasil, constituem ameaça à estabilidade democrática. Diante da expansão da pobreza e das desigualdades sociais, associada a uma crise política vivenciada pelo país, vem ocorrendo um processo de desconsolidação democrática e de desinstitucionalização dos direitos, impossibilitando a construção de uma cidadania participativa. O ceticismo e o afastamento dos cidadãos da esfera da política comprometem atitudes e comportamentos favoráveis à participação, cooperação, confiança interpessoal e de apoio ao regime democrático. As crescentes desigualdades sociais indicam a necessidade de se efetivar uma política que garanta oportunidades de trabalho e renda, melhoria da qualidade de vida e eqüidade social.

Esta seção buscou identificar a maneira como os cidadãos toledanos percebem o funcionamento da democracia e como atuam em 
relação aos canais de participação política. O conjunto de dados examinados evidenciou uma predisposição positiva entre os cidadãos para participar, especialmente dos canais informais da política. No entanto, em termos comportamentais foi constatada uma baixa participação, o que assinala uma cultura política marcada pela incongruência entre as atitudes e o comportamento político.

\section{Considerações Finais}

O conjunto de dados examinados evidencia uma expressiva descrença dos cidadãos nas instituições democráticas. Os fatores determinantes dessa descrença estão associados à avaliação negativa feita em relação à atuação dos políticos e às crescentes denúncias de corrupção na política. Da mesma forma, os motivos da baixa participação estão ligados à desinformação, à desmotivação, ao desinteresse sobre o que acontece na política. As pessoas não se sentem estimuladas a participar e a intervir no processo político, a não ser pela via eleitoral.

Um dos desafios da democracia brasileira consiste em solidificar um sistema político pautado no desenvolvimento de uma cidadania política e social e consolidar uma cultura política democrática, baseada na participação, na confiança recíproca e na solidariedade social. A plena democratização deve preencher o hiato entre a igualdade proposta pelo regime político e a desigualdade material que gera a miséria do povo brasileiro. Embora os cidadãos tenham o direito de expressar suas opiniões e de participar das decisões políticas, questiona-se a ausência de condições favoráveis para estimular tal participação. Verifica-se a ausência de um sentimento de competência cívica e de eficácia política, conceitos que se referem ao sentimento de competência e de vontade política para influenciar e participar no processo decisório.

Esse debate evidencia que a consolidação da democracia não é algo que possa ser alcançado com a simples adoção de leis e normas, mas depende de uma base normativa de apoio por parte dos cidadãos às instituições políticas. A mudança atitudinal dos atores políticos e a formação de uma cultura política compatível com os valores 
democráticos são de fundamental importância para promover a organização social e a legitimidade do sistema político.

Maria Salete Souza de Amorim é doutora em Ciência Política pela Universidade Federal do Rio Grande do Sul (UFRGS), Professora Adjunta da Universidade Estadual do Oeste do Paraná (UNIOESTE), Pesquisadora do Grupo de Pesquisa em Democracia e Desenvolvimento/UNIOESTE e do Grupo de Pesquisa Capital Social e Desenvolvimento Sustentável na América Latina/UFRGS.

E-mail: saleteamorim@uol.com.br.

\section{Referências:}

ALMOND, G.; VERBA, S. The Civic Culture. Political attitudes and democracy in five nations. Boston: Little Brown and Company, 1965.

1989.

(Ed.). The Civic Culture Revisited. California: Sage Publications,

BAQUERO, M. A vulnerabilidade dos partidos políticos e a crise da democracia na América Latina. Porto Alegre: Ed. UFRGS, 2000.

Globalização e Democracia Inercial. O que o Capital Social pode fazer na construção de uma sociedade participativa? In: BAQUERO, M.; CREMONESE, D. (Orgs). Capital Social. Teoria e Prática. Ijuí: Ed. Unijuí, 2006. p. 43-69.

BARBALHO, A. Estado Nacional, cultura nacional: dois momentos paradigmáticos. In: BARREIRA, I. e VIEIRA, S. (Orgs). Cultura e Política: tecidos do cotidiano brasileiro. Fortaleza: Edições UFC, 1998. p. 77-98.

BARREDA, M.; COSTAFREDA, A. La democracia importa, pero no basta para la igualdad. In: BINETTI, C.; CARRILLO, F. (Ed.). ¿Democracia con desigualdad? una mirada de Europa hacia América Latina. Colombia: Banco Interamericano de Desarrollo, 2004. p.115-141.

BEZERRA, M. O. Corrupção: um estudo sobre poder público e relações pessoais no Brasil. Rio de Janeiro: Relume-Dumará, 1995.

BILAC, M. B. B. Política Local e Coronelismo. Um estudo sobre as elites política de Rio Claro. Caderno CRH, Salvador, n. 26/27, p. 291-314, jan./dez. 1997.

CAMP, R. A. (Ed). Citizen Views of Democracy in Latin America. Pittsburgh: University of Pittsburgh Press, 2001. 
FAGEN, R. R.; TUOHY, W. S. Politics and Privilege in Mexican City. Califórnia: Stantford Universtity Press, 1972.

HASS, M. Os partidos políticos e a elite chapecoense. Um estudo de poder local (1945-1965). Chapecó: Argos Ed. Universitária, 2001.

INGLEHART, R. Cultura e democracia. In: HARRISON, L.; HUNTINGTON, S. (Orgs). A cultura importa. Rio de Janeiro: Record, 2002.

JARA, C. J. Construindo o poder local. Caderno $C R H$, Salvador, n. 26/27, p. 211-233, jan./dez. 1997.

KERBAUY, M. T. M. A morte dos coronéis: política interiorana e poder local. Araraquara/ São Paulo: FCL - Laboratório Editorial - Unesp / Cultura Acadêmica Ed., 2000.

LAMOUNIER, B.; SOUZA, A. de. Democracia e Reforma Institucional no Brasil: uma cultura política em mudança. Dados- Revista de Ciências Sociais, Rio de Janeiro, v. 34, n. 3, p. 311-347, 1991.

MADUEÑO, L. E. Sociología Política de la Cultura. Una Introducción. Mérida-Venezuela: Universidad de los Andes, Centro de Investigaciones de Política Comparada, 1999.

NAZZARI, R. K. Socialização política e construção da cidadania no Paraná. Cascavel: Edunioeste, 2002. (Coleção Thésis).

OLIVEIRA, R. C. O silêncio dos vencedores. Genealogia, classe dominante e Estado no Paraná. Curitiba: Moinho do Verbo, 2001.

PATEMAN, C. The Civic Culture: A Philosophic Critique. In: ALMOND, G.; VERBA, S. (Ed.). The Civic Culture Revisited. Califórnia: Sage Publications, 1989. p. 57-102.

PUTNAM, R. D. Comunidade e Democracia: a experiência da Itália Moderna. Rio de Janeiro: FGV, 2002.

RENNÓ, L. Instituições, cultura política e lógica da desconfiança numa cidade brasileira. In: BAQUERO, M. (Org.). Desafios da democratização na América Latina. Debates sobre Cultura Política. Porto Alegre/ Canoas: Ed. UFRGS/ Centro Universitário La Salle, 1999. p. 103-132.

RID - Rede Interamericana de Democracia. Índice de Participação Cidadã. Relatório Regional. Buenos Aires, Setembro. 29p. Disponível em: http://www.redinter.org/programas/indice/43622. Acesso em: 2005.

SCHIMDT, J. P. Juventude e Política no Brasil: a socialização política dos jovens na virada do milênio. Santa Cruz do Sul: EDUNISC, 2001. 
SOARES, G. A. D. A Democracia Interrompida. Rio de Janeiro: Editora FGV, 2001.

SOUZA, A. C. Um Novo Paradigma de Cultura Política na América Latina: para compreender o Brasil. In: BAQUERO, M. (Org). Democracia, partidos e cultura política na América Latina. Porto Alegre: Ed. Kuarup/NUPESAL, 1989. p. 137-176.

STOLLE, D. e HOOGHE, M. Emerging Repertoires of Political Action? A review of the debate on participation trends in Western societies. Paper presented at the ECPR Joint Sessions, Uppsala (Sweden), April 13-18, 2004. 